\title{
Reflections on NISO plus or scholarly communications pre-COVID - how the world has changed
}

\author{
Sara Rouhi* \\ Director of Strategic Partnerships, Public Library of Science (PloS), Washington, DC, USA
}

\begin{abstract}
This brief paper offers a look back at the inaugural NISO Plus conference that was held February 23-25, 2020 in Baltimore, MD, USA and provides the author's perspective on the themes that she identified over the three days of the conference.
\end{abstract}

Keywords: NISO plus, Covid-19, scholarly communication

The first annual NISO Plus conference took place in February of 2020 and reflecting on the meeting months later (during a pandemic-filled spring and early summer) is a bit like looking at old photographs. "Oh, yeah, conferences! I remember those...Are those still a thing?" Close quarters. Face-to-face meetings. Crowded banquet halls and meeting sessions.

And yet, even NISO Plus didn't escape COVID-19. In March, Todd Carpenter, NISO Executive Director, thoughtfully contacted all participants to disclose that a conference attendee had since been diagnosed with COVID-19. Of course there was no way of knowing if that person was positive during the conference or contracted the virus at the conference but, given the realities of international travel and attendees as well as the spread in the US by February, it's quite possible this person wasn't alone. So our new reality was with us at NISO Plus, even if we didn't know it at the time.

And yet, with all that, in many ways the scholarly communication universe remains the same, albeit in hyperdrive. While some topics from the February meeting may feel less urgent, the majority of discussion topics and the meta-issues that they represent are more urgent than ever.

The conference revolved around the usual program fare of \#scholcomm discussion: data sharinglinking-management, AI, standards (of course), open access (and to some extent, transformative agreements), impact measures and metrics, and accessibility and search. At the same time it began to touch on some of the meta-issues that the scholarly communication community as a whole is only beginning to grapple with - equity in access to peer-reviewed research, grant funding, and standards in assessment, for example.

These discussions have historically been difficult given the number of stakeholders involved, their competing interests, challenges around collective action, and increasingly limited resources. Naturally

E-mail: srouhi@plos.org. 
given NISO and NFAIS' specific foci - standards and emerging technology - the conference had to stay "close to home" in terms of content.

In my closing remarks on Day 1, Jason Griffey and I summarized our key findings and takeaways to participants. At the time I observed that between conference Twitter and in-persons sessions (remember those?!) several meta-themes were arising. Since the conference, those meta-themes seem more important than ever. The current crisis has a way of underscoring fractures in systems that we already knew we had.

(1) The imperative to be specific - We live in a wishy-washy world. Whether it's presidential pronouncements on coronavirus or keynote presentations at conferences, it's easy for sweeping claims and vague assertions to overrun our thinking and our language. To tackle the challenges we're facing currently and post-pandemic, both as an industry and society, we're going to have to be specific, attending to nuance, detail, and the tangles that come with them. My challenge to conference attendees was to bring that nuance to their discussion online and in person.

(2) Who isn't here? - Power and privilege dynamics undergird every interaction and structure with which we engage. We were all able to come together in person for vibrant discussions thanks to the relative wealth and privilege of our industry. NISO's commitment to DEI ensured global representation as well as a diversity of professional groups and career stages. That was a NISO priority.

Whether it's access to COVID-19 testing or access to vital pay-walled research, every ecosystem has winners and losers, haves and have-nots. As we confront the current paradigm shift to a more open scholarly communication environment (catalyzed in huge part by sweeping mandates from Northern European and American funders - a community of "haves"), we have to wrestle with the realities of those inequities and how our choices now may reinscribe them in years to come. Just as bungling and failed interventions in the UK and US have led to thousands of unnecessary deaths and cataclysmic economic hardship, hasty "works for me" solutions in our industry have already planted weeds that will be difficult to root out. Organizations must follow NISO's lead and work tirelessly (no doubt, with many stumbles) to consciously engage with these inequities.

(3) "I always thought that..."- Paradigm shifts and world historical events have a way of forcing us to confront long held assumptions of "essential truth". Often these "givens" belie an issue's inherent complexity or rely on a status quo consensus that is "easy". These truths have to be reexamined. For example, when various scholarly communication stakeholders trumpet "open is always better", questions need to arise: Open for whom? In what context? Within what constraints? What are the costs we're willing to pay for such an assumption? What are the unintended consequences of such efforts?

Assumptions undergirding Plan S, for example, are a case in point. Plan S' efforts to catalyze a faster transition to open access by fiat are commendable and demonstrate that community's commitment to a major, accelerated paradigm shift.

That said, its largely homogenous community of supporters and endorsers generated initial requirements in 2018 that left communities across the publishing ecosystem reeling. Scholarly societies scrambled to determine how/if revenue losses from subscriptions were tenable. Those leading the Green OA charge and institutional repositories - vital infrastructure for different communities and disciplines - saw little room for their approach to OA reflected in the principles. Communities that have long eschewed article charges in favor of a community-driven, non-commercial shared infrastructure saw another mandate from the "Global North" that, to them, appeared to completely ignore publishing practices in other parts of the world. To cOAlition S' credit, they always welcomed feedback and amended their principles and compliance requirements to address some of these concerns. 
Privately, stakeholders in the Plan S community have frankly admitted that their principles work best for their stakeholders and so the unintended consequences of their work - entrenching article charges for authors and facilitating the recreation of new "big deals" aka transformative agreements in the name of transparent article by article itemization - are worth it.

Mistakes, recognition, and evolution are a critical part of reexamining our assumptions in light of new information and circumstances. COVID-19 has made that kind of difficult reflection essential for many aspects of life. (Do I really need to work in an office? Oh, so that's what teachers do. I guess I can grocery shop less often. Do I really need to eat so much meat?)

The questions raised at NISO Plus and underscored by our current global circumstances will give us years of work and many hours of difficult discussions. We must tackle those challenges head on, with courage, accepting failure as a necessary step to evolution, but never as an excuse for complacence.

My thanks to Todd and the NISO team for making the last \#scholcomm meeting before lockdown such a fruitful and stimulating place for discussion. Todd always exhorts the community to walk away from such events with plans for action. My question to colleagues and friends in the community: What are yours?

Thanks the generous sponsorship of Cadmore Media and Figshare respectively, the NISO video portal and NISO Plus repository for then 2020mconference are available. You can find videos of key presentations (keynotes, the Miles Conrad Award session, and an edited version of the Engaging with NISO session) on our Cadmore portal, while our Figshare repository includes slides for all available NISO Plus presentations.

Author update as of June 2020: Since this article was first drafted in late May 2020, we have witnessed a global movement to fight systemic racism and policy brutality against the black community in the US. This movement exploded following the devastating murder of George Floyd and the shocking use of force used by law enforcement in subsequent protests against his murder. These recent developments underscore more than ever how institutions such as NISO and the scholarly communication community must commit more broadly to antiracism at every level. The systemic inequities for Black, Indigenous, and People of Color (BIPOCs) in academia, publishing, and scholarly communications run deep. It is incumbent on all those in positions of power to deeply scrutinize and reshape these communities on antiracist principles. Black lives matter. 